\title{
"Axillary Space Obliteration"-An Effective Technique in Reducing Seroma Formation after Mastectomy and Axillary Dissection
}

\author{
Mohammed Abd Elgalil Elbalshy*, Asem Mostafa Fayed, Mahmoud Gamaleldeen Hagag
}

Faculty of Medicine, Menoufia University, Shebin El-Kom, Egypt

Email: *mohammed.balshy@yahoo.com

How to cite this paper: Elbalshy, M.A.E., Fayed, A.M. and Hagag, M.G. (2018) "Axillary Space Obliteration"-An Effective Technique in Reducing Seroma Formation after Mastectomy and Axillary Dissection. Advances in Breast Cancer Research, 7, 23-32.

https://doi.org/10.4236/abcr.2018.71003

Received: December 23, 2017

Accepted: January 22, 2018

Published: January 25, 2018

Copyright $\odot 2018$ by authors and Scientific Research Publishing Inc. This work is licensed under the Creative Commons Attribution International License (CC BY 4.0).

http://creativecommons.org/licenses/by/4.0/

\begin{abstract}
Introduction: Seroma is the commonest complication of breast cancer surgery, and although its consequences most often cause no more than discomfort and anxiety, more important sequelae include flap necrosis and wound dehiscence. Seroma management can be difficult and frustrating for both the patient and surgeon. Numerous methods to reduce post-mastectomy seroma formation have been tried with no consistent success. Methods: Sixty patients were prepared for modified radical mastectomy. Of those, the study group contains 30 patients and the control group contains 30 patients. Study group had axillary space obliteration while the other had the conventional procedure; total drain outputs were recorded daily for all patients prior to drain removal. The drains were removed when the daily drainage was less than 30 ml. Results: This study contains 60 patients, and the study group contains 30 patients, and the control group contains 30 patients. Age, tumor size, No. of positive lymph nodes were of no significant differences to be more concise on the effect of axillary space obliteration. The mean of day of drain removal in the control group was $13.2 \pm 1.0$ days ( 9 - 18 days) with a mean of total drain output of $(4700 \pm 90.3 \mathrm{ml})(3722$ - 4930) while the mean in the study group of day of drain removal was $7.1 \pm 1.3$ days $(6-12)$ with a mean of total drain output of $1530 \pm 422 \mathrm{ml}$ (range $600-2100 \mathrm{ml}) \mathrm{p}<0.001$. Conclusion: Obliteration of axillary space is a valuable procedure that significantly decreases seroma after mastectomy and axillary dissection.
\end{abstract}

\section{Keywords}

Seroma, Mastectomy, Axillary Space, Obliteration 


\section{Introduction}

Seroma represents the most common complication of breast cancer surgery [1]. Although seroma formation is very common after mastectomy reaching up to $81 \%$ [2] [3], the exact etiology of it remains obscure, and this has made many surgeons to consider it as a necessary event rather than a complication. However, it may be complicated by secondary infection, wound dehiscence, delayed wound healing, and delayed start of adjuvant therapy and as a result higher expenses [4].

This by far will represent a burden for the surgeon as well as more discomfort, more anxiety for the patient. And due to the controversy regarding the etiology of seroma, management will be difficult and frustrating.

So we have many techniques that aimed at reducing seroma formation e.g. wound bandaging, talcum powder, fibrin glue, ultrasonic knife, flap fixation, usage or non-usage of vacuum suction drains [5] [6].

However, none of these had proved to be effective in reducing seroma and its associated complications. It is accepted that the largest potential dead space is the empty axillary apex after axillary dissection or indeed that seroma formation is contributed significantly by disruption of axillary lymphatics. It follows that obliteration of this space may be valuable.

\section{Aim of Work}

To study the effect of axillary space obliteration after modified radical mastectomy on post-operative seroma formation.

\section{Methods}

This study is a randomized controlled trial that took place in Surgery Department, Menoufia University Hospital, from August 2016 to November 2017. The protocol of this research has been reviewed by our research ethics committee in the Faculty of Medicine, Menoufia University at its meeting in July, 2016 with reference number (40-6-2016).

This study was performed on 60 patients who were referred to outpatient clinic. The sample size was calculated as 30 patients for each group (study group and control group).

Those 60 patients were recruited to our study according to the following inclusion and exclusion criteria. The patients enrolled as the inclusion criteria are:

1) Patients with breast cancer and planned for modified radical mastectomy willing to participate in the study and to sign the informed consent.

2) Confirmed lymph node metastasis (diagnosed by preoperative biopsy or intraoperative sentinel lymph node biopsy) requiring axillary lympadenectomy.

3) No previous history of axillary surgery.

And exclusion criteria were:

a) Patients with advanced breast cancer and arranged for palliative mastectomy. 
b) Patients arranged for conservative breast surgery and sentinel lymph node.

c) Patients arranged for breast reconstruction at the same session. Then, they were randomly allocated to either the control or study groups. Random sequence was generated by Microsoft Excel program using random functions.

The surgeon was given randomly generated treatment allocations within sealed envelops. Once a patient has consented to enter the trial, this envelope was opened and the patient then underwent the allocated surgery. The technique was performed by a single surgeon and involved skin flap dissection and excision of the breast with pectoral fascia and the dissection of axillary lymph nodes (level II/III) were performed with a diathermy (Figure 1(a)). Control of the small bleeding vessels was sustained with coagulate mood of diathermy. First three to four interrupted sutures were placed between pectoralis major and minor then suturing the anterior and lateral portion of superior mastectomy skin flap down to the free edge of pectoralis major and the lateral chest wall was done using a continuous $2 / 0$ vicryl stitch to completely obliterate the axillary fossa leaving the remainder of the mastectomy cavity (Figure 1(b), Figure 1(c), Figure $1(\mathrm{~d}))$. $16 \mathrm{~F}$ suction drains were placed at surgery in all patients with the tip placed within the mastectomy cavity outside the obliterated axilla; then pressure dressing was applied. Total drain outputs were recorded daily for all patients prior to drain removal the drains were removed when the daily drainage was less than $30 \mathrm{ml}$. At the two-week post-operative visit, the presence and severity of seroma was recorded. This was graded mild (asymptomatic), moderate (symptomatic but not requiring intervention, or severe (symptomaic requiring intervention) patients were followed up till seroma, when occurs, has completely resolved through repeated aspirations and this has extended up to two months in some cases. Statistical data analysis was done using Chi-square, and Student $\mathrm{t}$-test to determine significance in seroma incidence between both groups.

\section{Results}

Patients' age, size of tumour, number of positive lymph nodes and laterality were comparable between both groups with no significant difference between them (Table 1).

The mean age of patients among the study group was $48.3 \pm 2.3$ (35 - 71 years) while among the control group was $49.1 \pm 3.4$ (37 - 77 years) with no significant difference between both groups. The laterality of operations was 25 (41.7\%) left and 35 (58.3\%) right. Types of pathology included invasive ductal carcinoma, ductal carcinoma in situ, and mixed invasive ductal/lobular carcinoma.

Fifty three patients (88.3\%) had invasive tumours (80\% IDC, $20 \%$ mixed IDC/ILC). Sizes of tumour in study group were $33.1 \mathrm{~mm}$ (range $8-71$ ) and this also was not significantly different from control group $35.2 \mathrm{~mm}(13-88)$. Drains remained in situ for 6 - 18 days.

At drain removal, (Figure 2) total drain output was measured and recorded. Mean total amount of drain output for the study group was $1530 \pm 422 \mathrm{ml}$ 


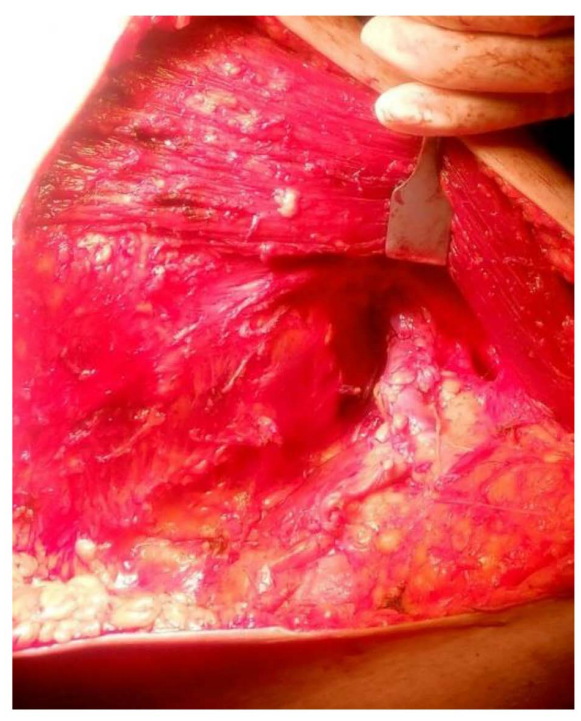

(a)

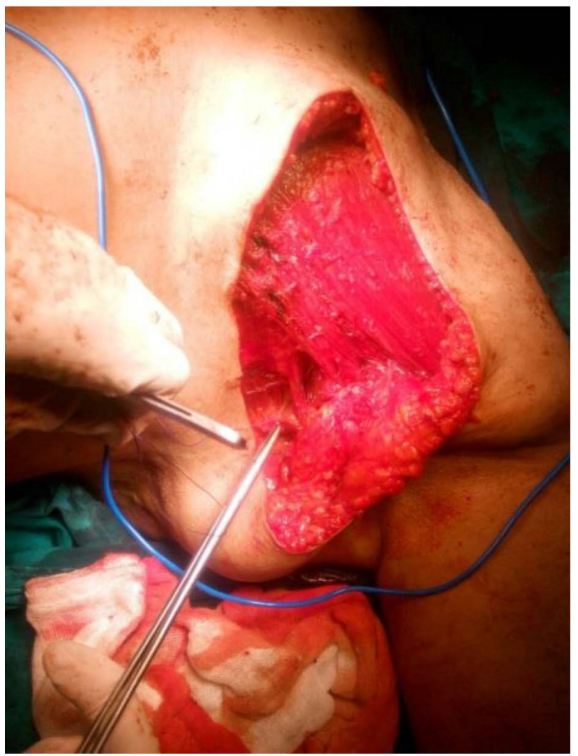

(c)

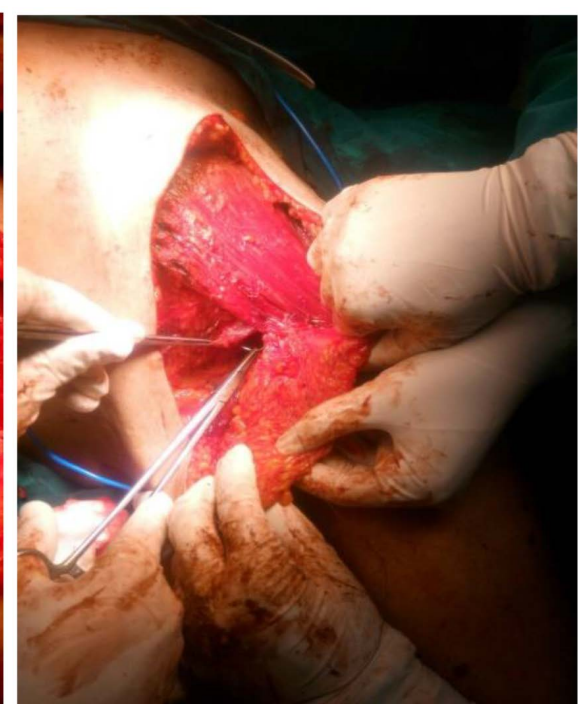

(b)

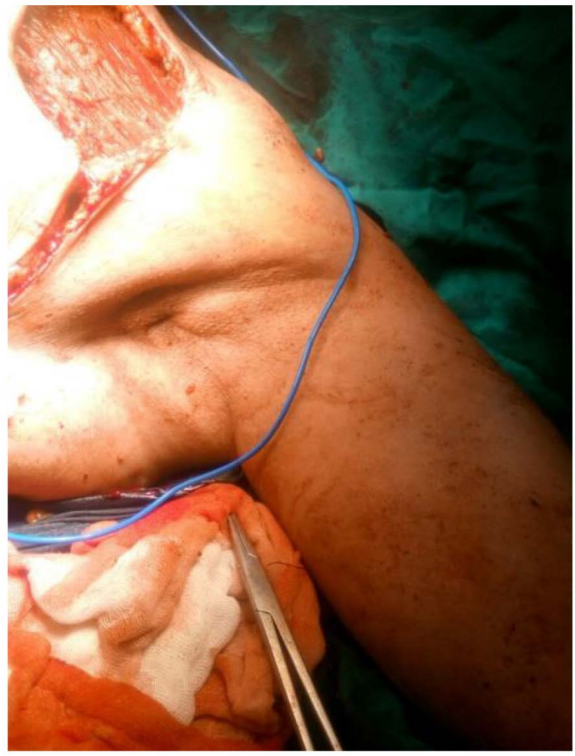

(d)

Figure 1. Intra-operative photographs showing axillary space obliteration. (a) Axillary fossa potential dead space after mastectomy and axillary clearance; (b) Antero- lateral part of Superior mastectomy flap sutured to free edge of pectoralis major and lateral chest wall obliterating the axillary space after Interrupted sutures to appose pectoralis major and minor (c) picture after complete obliteration of axillary space; (d) final external picture.

(range $600-2100 \mathrm{ml}$ ) over a mean of $7.1 \pm 1.3$ days. While the control group had a mean drain output of $(4700 \pm 90.3 \mathrm{ml})$ which revealed significant reduction in amount among the study group by $35 \%$ (Figure 3 ) and the difference between both groups was statistically significant (Table 2).

Time of drain removal was different between both groups as the mean of the days before drain removal was $7.1 \pm 1.3$ in the study group while in the control group was $13.2 \pm 1.0$ days (Table 3 ). 


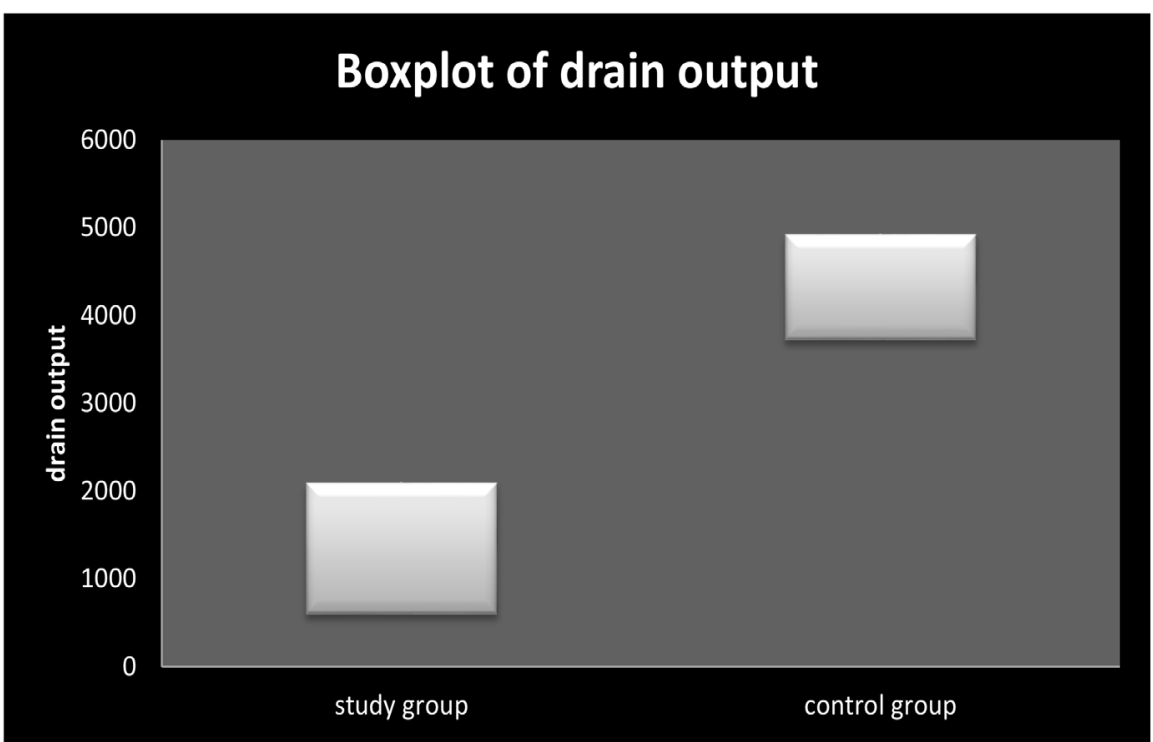

Figure 2. Boxplot distribution of drain output in both control and study groups.

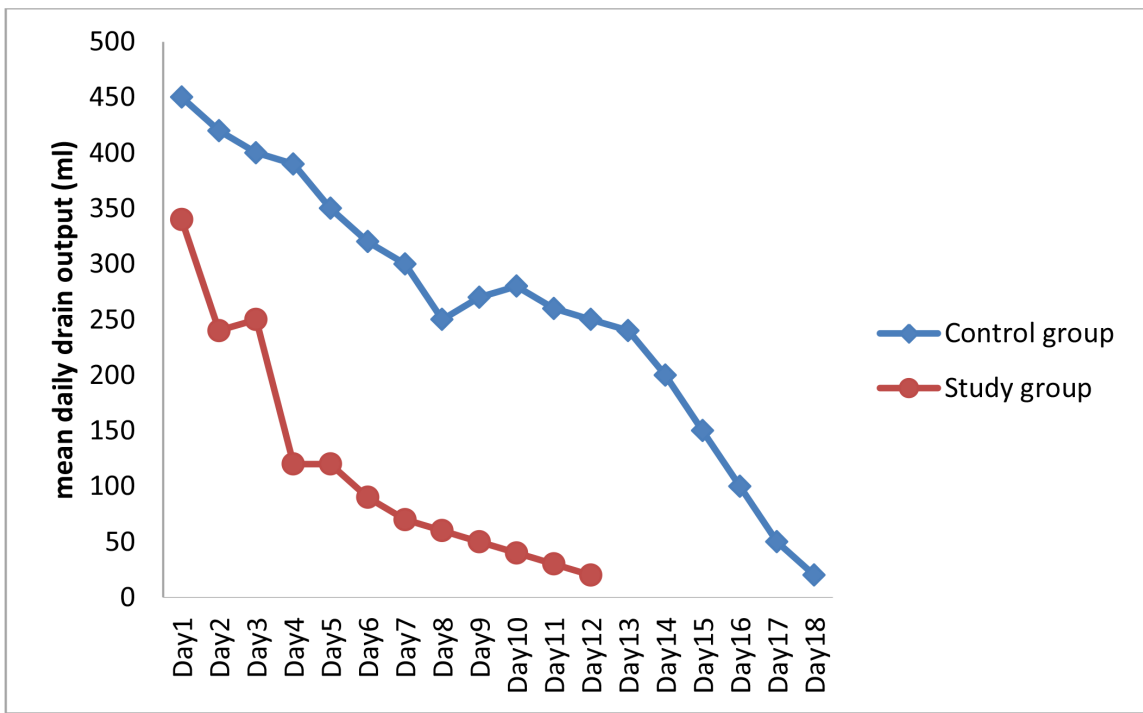

Figure 3. Distribution of patients according to daily drain output (ml) .Significant reduction of the daily amount of drain output in the study group who undergone axillary obliteration $\mathrm{p}<0.05$.

Table 1. Comparison of results between study group and control group.

\begin{tabular}{ccc}
\hline Variable & Study group & Control group \\
\hline Mean age & $48.3 \pm 2.3(35-71)$ & $49.1 \pm 3.4(37-77)$ \\
Size of tumour $(\mathrm{mm})$ & $33.1(8-71)$ & $35.2(13-88)$ \\
No. of lymph nodes removed & $14.8(8-25)$ & $12.6(10-23)$ \\
No. positive lymph nodes & $8.2(0-16)$ & $7.8(2-14)$ \\
Laterality (\% Right) & $57.1 \%$ & $59.0 \%$ \\
Hypertension & $10 / 30(33.3 \%)$ & $9 / 30(30 \%)$ \\
Diabetes mellitus & $7 / 30(23.3 \%)$ & $5 / 30(16.7 \%)$
\end{tabular}


Table 2. Comparison between both groups regarding total drain output.

\begin{tabular}{|c|c|c|c|c|c|c|c|}
\hline \multirow{3}{*}{$\begin{array}{l}\text { Total drain } \\
\text { output (ml) }\end{array}$} & \multicolumn{3}{|c|}{ Control group $(n=30)$} & \multicolumn{3}{|c|}{$\begin{array}{l}\text { Axillary obliteration } \\
\qquad(\mathrm{n}=30)\end{array}$} & \multirow{2}{*}{$\begin{array}{c}\text { Test of } \\
\text { significance } \\
\text { P value }\end{array}$} \\
\hline & Mean & $\pm \mathrm{SD}$ & Range & Mean & $\pm \mathrm{SD}$ & Range & \\
\hline & 4700 & 90.3 & $3722-4930$ & 1530 & 422 & $600-2100$ & $\mathrm{p}<0.001^{* *}$ \\
\hline
\end{tabular}

${ }^{*} \mathrm{p}$ values less than 0.05 is statistically significant.

Table 3. Comparison between both groups regarding time of drain removal.

\begin{tabular}{|c|c|c|c|c|c|c|c|}
\hline \multirow{3}{*}{ Days before drain } & \multicolumn{3}{|c|}{ Control group $(n=30)$} & \multicolumn{3}{|c|}{$\begin{array}{l}\text { Axillary obliteration } \\
\qquad(\mathrm{n}=30)\end{array}$} & \multirow{2}{*}{$\begin{array}{c}\text { Test of } \\
\text { significance } \\
\text { p value } \\
t=20.3\end{array}$} \\
\hline & Mean & $\pm \mathrm{SD}$ & Range & Mean & $\pm \mathrm{SD}$ & Range & \\
\hline & 13.2 & 1.0 & $9-18$ & 7.1 & 1.3 & $6-12$ & $\mathrm{p}<0.001^{* *}$ \\
\hline
\end{tabular}

${ }^{*} \mathrm{p}$ values less than 0.05 is statistically significant.

For postoperative complications, in the study group 93.4\% showed no postoperative complications. 3.3\% showed wound infection, 3.3\% developed ischemic flaps. while in the control group $80.2 \%$ passed without postoperative complications, 9.9\% developed wound infection, 3.3\% developed ischemic flaps, $6.6 \%$ showed wound dehiscence (Figure 4).

\section{Discussion}

There are many studies done on different risk factors that may be involved in seroma formation like, age of patient, type of surgery, tumor size, number and positivety of lymph nodes however the results of them are not similar, and in any case, the majority of these risk factors are unmodifiable. In our study either age, tumor size, number of positive lymph nodes did not significantly affected incidence of seroma, on the same way Gonzalez et al. (2003) [7] had found the same results to us, also at 2004 Hashemi et al. [8] had found no significant effect for age ,tumor size, or nodal involvement on seroma formation. On the opposite side Lumachi et al. (2004) [5] reached to different results regarding significant effect for tumor size and nodal involvement on seroma formation.

Then surgeons began to modify either the technique or the life style of patients over the years including shoulder immobilization, usage of tranexamic acid, change of surgical instrument either electrocautery or ultrasonic knife, etc. [9].

But the results of these studies are inconsistent, e.g. contrary to popular belief electrocautery revealed to be a contributing factor increasing incidence of sero$\mathrm{ma}$, and as regards to arm movement some found benefit of delaying arm movement depending on that chest wall motion and shoulder use create shearing forces that hinders flap adherence and this will act as a pump forcing lymph into the empty axillary fossa [10], however others have found no benefit of delaying arm movement [11] [12].

We believe that distribution of axillary lymphatics shares to a greater extent than mastectomy flaps in seroma formation and so reliably obliterating the 


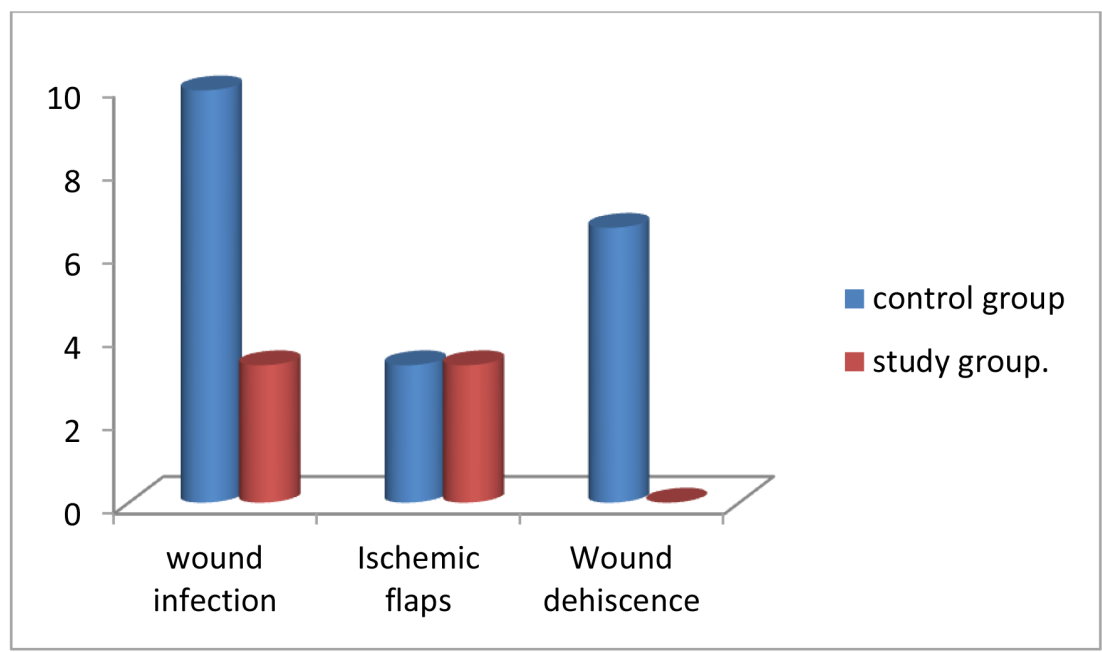

Figure 4. Distribution of patients according to postoperative complications.

axillary space can considerably reduce postoperative drainage volume in this small group of patients. More importantly, this technique significantly reduces clinically apparent seromas after drain removal, thereby reducing the consequences of patient anxiety, discomfort, and added morbidity.

Previous studies regarding mechanical closure of the dead space are small in number and poor in quality and non have clearly demonstrated difference. Although the findings that do not support a pressure garment or compression dressing, in contrast to that flap fixation using sutures appears to be beneficial and reduces seroma formation and subsequent aspirations, and even in BCS a drain may not be needed [13].

Several studies have looked into fixing skin flaps to underlying muscle in an attempt to minimise dead space. Halsted first described flap fixation in 1913 [14] and since, surgeons began to introduce different techniques to secure flaps and thereby close dead space. Some have used external sutures passing through the flap from the underlying muscle, but of course these may be complicated by either wound infection or local skin necrosis. Coveney et al. [15] as well as O'Dwyer [16] demonstrated that drainage volumes and seroma formation were significantly reduced when dead space was obliterated by suturing flaps to muscle down the skin closure suture line. Chilson et al. [17] advocated a similar tacking procedure ,but tacked down the entire flap area using interrupted sutures.

If it is believed that the largest potential dead space is the empty axillary apex after axillary dissection or indeed that seroma formation is contributed significantly to by disruption of axillary lymphatics, it means that closure of this space may prove useful. In our study that involved obliteration of the axillary space we had found that this technique had significantly reduced seroma formation also it had reduced the time needed for drain removal $\left(\mathrm{p}<0.001^{*}\right)$. A few studies introduced the concept of axillary padding to reduce drainage volumes after axillary surgery. The axillae were padded with nearby tissue, and outcomes in terms 
of seroma formation were excellent. However, both main studies [18] [19] carried out a limited axillary dissection, and were carried out on patients undergoing breast conservation.

On contrary to our results there is a study performed in Thailand [20] and it was involving 18 patients their technique involved suturing the skin flap to underlying muscle at 3 points in the mid-axillary line, and found no significant difference of seroma incidence at the axilla measured by ultrasound at two weeks this may be due to small number of patients in that study. In the same way with us, Yiping Gong, MB [21], studied 200 breast cancer patients randomly divided into 2 groups: group 1 was operated by using ligation all of the tissue connecting axillary vein bundles to the specimen, suturing the anterior edge of the latissimus dorsi to the chest wall, and fix the skin flap to the underlying muscle by subcutaneous sutures while group 2 was operated on using the conventional technique. The drainage volume for patients in group 1 was significantly less than that for patients in group $2(\mathrm{p}<0.01)$. The duration of drainage in group 1 was shorter than that in group $2(\mathrm{p}<0.01)$. The incidence of seroma formation in the study group (2\%) was significantly less than that in group $2(14 \%)$. Also in the same way with us Chand N, et al. at (2012) [22] in their study on a small group (24 patients) found significant reduction $(\mathrm{p}<0.01)$ of drainage volumes and incidence of seroma in the group they had closed off the axillary space from the remainder of the mastectomy cavity they reported an incidence of seroma (62.5\%). 90\% was in the control group and $42.5 \%$ in the study group with a reduction of about $65 \%$. and in another study published by Faisal M, et al. at (2016) [23] on 64 patients also they found significant reduction in seroma formation as well as time of drain removal after they have used similar technique ( $p$ $<0.01)$.

\section{Conclusion}

Obliteration of axillary space is a simple technique that reduces significantly the total amount of seroma formation postoperatively, the psychological burden of long time drain, postoperative visits for drain follow-up, and complications related to seroma accumulation after breast cancer surgery. However, this technique should be tried on a much wider scale to prove its validity in decreasing the incidence of seroma formation and its subsequent complications.

\section{Conflict of Interest}

The authors declare that they have no conflict of interest.

\section{Ethical Approval}

All procedures performed in the study were in accordance with the ethical standards of the institutional and/or national research committee and with the 1964 Helsinki Declaration and its later amendments or comparable ethical standards. 


\section{Funding}

No source of funding.

\section{References}

[1] Aitken, D.R. and Minton, J.P. (1983) Complications Associated with Mastectomy. Surgical Clinics of North America, 63, 1331-1352.

https://doi.org/10.1016/S0039-6109(16)43192-0

[2] Woodworth, P.A., McBoyle, M.F., Helmer S.D. and Beamer, R.L. (2000) Seroma Formation after Breast Cancer Surgery: Incidence and Predicting Factors. The American Journal of Surgery, 66, 444-451.

[3] Roses, D.F., Brooks, A.D., Harris, M.N., et al. (1999) Complications of Level I and II Axillary Dissection in the Treatment of Carcinoma of the Breast. Annals of Surgery, 230, 194-201. https://doi.org/10.1097/00000658-199908000-00009

[4] Iida, S., Furukawa, K., Yanagihara, K., et al. (2008) An Analysis of Factors That Influence the Duration of Suction Drainage in Breast Cancer Surgery. Journal of Nippon Medical School, 75, 332-336. https://doi.org/10.1272/jnms.75.332

[5] Lumachi, F., Brandes, A.A., Burelli, P., Basso, S.M., Iacobone, M. and Ermani, M. (2004) Seroma Prevention Following Axillary Dissection in Patients with Breast Cancer by Using Ultrasound Scissors: Aprospective Clinical Study. European Journal of Surgical Oncology, 30, 526-530. https://doi.org/10.1016/j.ejso.2004.03.003

[6] Saeb-Parsy, K., Athanassoglou, V. and Benson, J.R. (2006) Talc Seromadesis: A Novel Technique for the Treatment of Chronic Seromas Following Breast Surgery. The Breast Journal, 12, 502-504. https://doi.org/10.1111/j.1075-122X.2006.00317.x

[7] Gonzales, E.A., Saltzstein, E.C., Riedner, C.S. and Nelson, B.K. (2003) Seroma Formation Following Breast Cancer Surgery. The Breast Journal, 9, 385-388.

https://doi.org/10.1046/j.1524-4741.2003.09504.x

[8] Hashemi, E., Kaviana, A., Najafi, M., Ebrahimi, M., Hooshmand, H. and Montazeri, A. (2004) Seroma Formation after Surgery for Breast Cancer. World Journal of Surgical Oncology, 2, 44. https://doi.org/10.1186/1477-7819-2-44

[9] Pogson, C.J., Adwani, A. and Ebbs, S.R. (2003) Seroma Following Breast Cancer Surgery. European Journal of Surgical Oncology, 29, 711-717. https://doi.org/10.1016/S0748-7983(03)00096-9

[10] Purkayastha, J., Hazarika, S., Deo, S.V., Kar, M. and Shukla, N.K. (2004) Post-Mastectomy Chylous Fistula: Anatomical and Clinical Implications. Clinical Anatomy, 17, 413-415. https://doi.org/10.1002/ca.10239

[11] Lindsey, W.H., Masterson, T.M., Spotnitz, W.D., Wilhelm, M.C. and Morgan, R.F. (1990) Seroma Prevention Using Fibrin Glue in a Rat Mastectomy Model. Archives of Surgery, 125, 305-307. https://doi.org/10.1001/archsurg.1990.01410150027005

[12] Moore, M.M., Nguyen, D.H. and Spotnitz, W.D. (1997) Fibrin Sealant Reduces Serous Drainage and Allows for Earlier Drain Removal after Axillary Dissection: A Randamiosed Prospective Trial. The American Journal of Surgery, 63, 97-103.

[13] Classe, J.M., Berchery, D., Campion, L., et al. (2006) Randomized Clinical Trial Comparing Axillary Padding with Closed Suction Drainage for the Axillary Wound after Lymphadenectomy for Breast Cancer. British Journal of Surgery, 93, 820-824. https://doi.org/10.1002/bjs.5433

[14] Halsted, W.S. (1913) Developments in the Skin Grafting Operations for Cancer of the Breast. Journal of the American Medical Association, 60, 416-418. 
https://doi.org/10.1001/jama.1913.04340060008004

[15] Coveney, E.C., O’Dwyer, P.J., Geraghty, J.G. and O’Higgins, N.J. (1993) Effect of Closing Dead Space on Seroma Formation after Mastectomy-A Prospective Randomised Clinical Trial. European Journal of Surgical Oncology, 19, 143-146.

[16] O'Dwyer, P.J. (1991) Axillary Dissection in Primary Breast Cancer. British Medical Journal, 302, 360-361. https://doi.org/10.1136/bmj.302.6773.360

[17] Chilson, T.R., Chan, F.D., Lonser, R.R., Wu, T.M. and Aitken, D.R. (1992) Seroma Prevention after Modified Radical Mastectomy. American Surgeon, 58, 750-754.

[18] Garnier, J.M., Hamy, A., Classe, J.M., Laborde, O., Sagot, P., Lopes, P., et al. (1993) A New Approach to the Axilla: Functional Axillary Lymphadenectomy and Padding. Journal of Gynaecology, Obstetrics and Reproductive Biology, 22, 237-242.

[19] Classe, J.M., Dupre, P.F., François, T., Robard, S., Theard, J.L. and Dravet, F. (2002) Axillary Padding as an Alternative to Closed Suction Drain for Ambulatory Axillary Lymphadenectomy: A Prospective Cohort of 207 Patients with Early Breast Cancer. Archives of Surgery, 137, 169-172. https://doi.org/10.1001/archsurg.137.2.169

[20] Benjasirichai, V., Piyapant, A., Pokawattana, C. and Dowreang, J. (2007) Reducing Postoperative Seroma by Closing of Axillary Space. Journal of the Medical Association of Thailand, 90, 2321-2325.

[21] Gong, Y., Xu, J., Shao, J., Cheng, H., Wu, X., Zhao, D., et al. (2010) Prevention of Seroma Formation after Mastectomy and Axillary Dissection by Lymph Vessel Ligation and Dead Space Closure: A Randomized Trial. The American Journal of Surgery, 200, 352-356. https://doi.org/10.1016/j.amjsurg.2009.10.013

[22] Chand, N., Aertssen, A.M.G. and Royle, G.T. (2013) Axillary "Exclusion"-A Successful Technique for Reducing Seroma Formation after Mastectomy and Axillary Dissection. Advances in Breast Cancer Research, 2, 1-6.

https://doi.org/10.4236/abcr.2013.21001

[23] Faisal, M., Abu-Elela, S.T., Mostafa, W. and Antar, O. (2016) Efficacy of Axillary Exclusion on Seroma Formation after Modified Radical Mastectomy. World Journal of Surgical Oncology, 14, 39. https://doi.org/10.1186/s12957-016-0801-0 